\title{
Youth friendly health services and role of outreach activities to improve access to services
}

\author{
Ruchi Sogarwal ${ }^{*}$ Murari Chandra, Sunil Mehra \\ MAMTA Health Institute for Mother and Child, New Delhi, India; ${ }^{*}$ Corresponding Author: ruchi.dr@gmail.com \\ Received 10 January 2013; revised 6 March 2013; accepted 9 April 2013 \\ Copyright (C) 2013 Ruchi Sogarwal et al. This is an open access article distributed under the Creative Commons Attribution License, \\ which permits unrestricted use, distribution, and reproduction in any medium, provided the original work is properly cited.
}

\section{ABSTRACT}

An attempt has been made to assess the Youth Friendly Health Services (YFHS) from the clients' perspectives and the role of outreach community-based approach (Youth Information Center, YIC) in improving access to services. A crosssectional study was undertaken in Arajiline and Hoskote blocks in Varanasi and Bangalore districts respectively using primarily a quantitative technique. A consecutive sample of 120 clients from 4 selected clinics was interviewed after seeking services from YFHS. Additionally, facility assessment of clinics and 8 FGDs were conducted among community members and the young people in the community. Majority of the clients $(90.8 \%)$ are aware that YFHS provide services to young males and females separately on specific day and time. Nearly $66 \%$ clients visited YFHS to sought treatment for three key health problems i.e. menstruation problems (25.4\%) followed by general illness (22.8\%) and swelling/itching of private parts (21.1\%). In Hosakote privacy was maintained during the consultation with the doctor, however, situation was relatively not better in Arajiline. Out of those clients who had visited YIC atleast once, 49 out of 53 in Arajiline and 51 out of 60 in Hasokote reported that the YIC stafflactivities had motivated them to sought services at YFHS. Study concludes that while majority of the clients were satisfied with the services at YFHS, there is a need for strengthening the existing "package" of the services. At facility level, reassurance about the privacy and confidentially and alternative ways to promote access and utilization of services by active involvement of young people is recommended. On the other hand, at outreach level, new technologies should be introduced to generate demand, intensive focus on adults in the community and integration of YIC with local governance and school environment is suggested so as to protect young people against poor health outcomes.

Keywords: Youth Friendly Health Services; Reproductive Sexual Health; Adolescent; India

\section{INTRODUCTION}

The Reproductive and Sexual Health (RSH) of young people is of immense importance in today's context. Evidences underlined that unintended pregnancies, initiation of sexual intercourse, stillbirth, morbidity and mortality related to pregnancy and sexually transmitted infections are common problems faced by the young [1-4]. Factors like knowledge and attitudes about the risk related to RSH and non availability of proper health system act as barriers in seeking services [5,6]. Access to primary-health services is seen as an important component of care, including preventive health for young people [7]. Studies from around the world indicate that young people are often unwilling or unable to obtain needed health services, which address these barriers $[8,9]$.

RSH needs of young people are underserved and provision of youth-friendly services alone is not sufficient to meet them. Access to services can be improved when health-service provision (or supply-side activities) combined with community based interventions (or demandside activities) to create a more supportive environment for adolescent care seeking and increased uptake of services $[10,11]$. In order to provide specific services for the unmet needs of adolescents and to improve RSH status of young people, MAMTA-Health Institute for Mother and Child (MAMTA-HIMC) [12] has taken an initiative to establish YFHS within the existing public health system by creating supportive environment in the community, 
enhancing capacity of service providers and advocacy with Government officials. To facilitate reach out to the young people, YIC was an innovative strategy of the project that has provided safe place to share information on RSH. The project was in line with the strategy of Government of India on Adolescent Reproductive and Sexual Health (ARSH) [13], however, provision of YIC was not a part of outreach plan of Government of India. The outcome of the project has motivated district officials to consider upscaling the project in entire district. For the purpose, a need was felt to assess the perceived understanding of the clients to guide future efforts of service delivery. Hence, an attempt was made to assess the YFHS from the clients' perspectives and the role of outreach activities in improving access to the services.

\section{METHODS}

A cross-sectional study was undertaken in four selected YFHS clinics (Rajatalab, Gangapur, Sulibele and Mugabla) of Arajiline and Hosakote blocks of Varanasi and Bangalore districts respectively using primarily a quantitative method. Facility assessment and Focus Group Discussions (FGDs) at community level were conducted to explore the context.

\subsection{Study Subjects}

A total of 120 clients who received services from clinics were selected using consecutive sampling technique. Sample size was worked out assuming $10 \%$ conservative estimate, 10\% relative error, 1.2 design effect and 95\% confidence interval. In addition, 8 FGDs were conducted with community members including school teachers, member of local governance, parents; and young people in the community covering $8-10$ participants in each discussion.

The inclusion/exclusion criteria for the study subjects considered were: age in the range of 15 - 24 years, residential of the selected study area, willingness to participate in the study, ability to understand the questions.

\subsection{Study Instrument and Data Domain}

Semi-structured Interview schedule was developed for exit interviews covering different domains for instance demographic characteristics, time spent on client-provider interaction, perception about privacy and confidentially, awareness about YIC activities, role of YIC, level of satisfaction etc.

A uniform guide was developed for FGD covering key domain on privacy-confidentiality, attitude of adults towards adolescent concerns, roles of outreach activities in improving access to services and suggestions for improvement of YIC services/activities. Structured Questionnaire was used to obtain information on staffing, training, infrastructure, supplies, and services.

\subsection{Ethical Review}

Ethical approval was sought from the Institutional Review Board. Informed consent was obtained from all the participants prior to the interview. The interviews were conducted under conditions of assured total anonymity.

\subsection{Data Collection and Analysis}

The data collection was done during January-April 2012 by trained research investigators. Descriptive statistics and chi-square test were employed for statistical analysis of quantitative data. In order to understand the differentials in level of client satisfaction, ratios of the levels of satisfaction among the clients of various groups to that of the clients of reference category are computed. A ratio value of less than 1 would mean that the levels of client satisfaction are relatively higher for clients in the reference group compared to other clients while a value of 1 would indicate no difference in the satisfaction level. Besides, the information of FGDs was analyzed manually by constant comparison, conceptualization and categorizing of data. The main concepts and themes within the data were identified. Each phrase was examined, classified according to the theme within it and considered in terms of its context in the discussion.

\section{RESULTS}

A total of 120 clients were interviewed (equal number of male and female) from both Arajiline and Hosakote blocks. The mean \pm SD age (in years) of the clients was $19 \pm 2.9$ in Arajiline and $21 \pm 1.7$ in Hosakote. Majority of the clients were educated up to high school and above (65.8\%), belonged to Other Backward Class-OBC (54.6\%). Further, $18.9 \%$ and $47.5 \%$ clients belong to the household who had monthly income less than 3000 and in the range of 3001 - 5000 (Table 1).

Considering objective of the article, findings have been organized in two sections, i.e. Assessment of YFHS and Role of outreach activities.

\subsection{Assessment of YFHS}

A set of characteristics associated with the "youth friendly services" was identified based on the literature available on assessment of YFHS [3-4,14]. Accordingly, the findings were organized based on the key characteristics as described under:

1) Awareness of YFHS and Services availed by the clients:

Majority of the clients in Arajiline $(\mathrm{n}=58)$ and Hosakote $(\mathrm{n}=51)$ are aware of YFHS that it provide services to males and females separately on specific day and time. Source of information on YFHS is predominantly YIC 
Table 1. Socio-demographic profile of clients seeking services at YFHS.

\begin{tabular}{|c|c|c|c|}
\hline $\begin{array}{l}\text { Background } \\
\text { characteristics }\end{array}$ & $\begin{array}{l}\text { Arajiline } \\
(\mathrm{n}=60)\end{array}$ & $\begin{array}{c}\text { Hosakote } \\
(\mathrm{n}=60)\end{array}$ & $\begin{array}{c}\text { Total } \\
(\mathrm{n}=120)\end{array}$ \\
\hline \multicolumn{4}{|l|}{$\begin{array}{l}\text { Age of the } \\
\text { respondent }\end{array}$} \\
\hline $15-19$ yrs & $32(53.3)$ & $11(18.3)$ & 43 (35.8) \\
\hline $20-24$ yrs & $28(46.7)$ & 49 (81.7) & $77(64.2)$ \\
\hline \multicolumn{4}{|l|}{ Religion } \\
\hline Hindu & $60(100.0)$ & $57(95.0)$ & 117 (97.5) \\
\hline Non-Hindu & - & $3(5.0)$ & $3(2.5)$ \\
\hline \multicolumn{4}{|l|}{ Caste/Tribe ${ }^{*}$} \\
\hline SC/ST & $4(18.6)$ & $11(18.6)$ & 15 (12.6) \\
\hline OBC & $51(85.0)$ & 14 (23.7) & $65(54.6)$ \\
\hline General & $5(8.3)$ & $34(57.6)$ & 39 (32.8) \\
\hline \multicolumn{4}{|l|}{$\begin{array}{c}\text { Educational } \\
\text { qualification }\end{array}$} \\
\hline Illiterate & $1(1.7)$ & - & $1(0.8)$ \\
\hline Upto middle school & $8(13.8)$ & $2(3.3)$ & $10(8.5)$ \\
\hline Upto high SCHOOL & $11(19.0)$ & 17 (28.3) & 28 (23.7) \\
\hline $\begin{array}{l}\text { Intermediate/High } \\
\text { secondary }\end{array}$ & $21(36.2)$ & 34 (56.7) & 55 (46.6) \\
\hline Graduate and above & 17 (29.3) & $7(11.7)$ & 24 (20.3) \\
\hline \multicolumn{4}{|l|}{ Marital status } \\
\hline Currently married & $13(21.7)$ & $11(18.3)$ & $24(20.0)$ \\
\hline Never married & $47(78.3)$ & 49 (81.7) & $96(80.0)$ \\
\hline \multicolumn{4}{|l|}{ Working status } \\
\hline Working & $22(36.7)$ & 34 (56.7) & $56(46.7)$ \\
\hline Not working & 38 (63.3) & $26(43.3)$ & $64(53.3)$ \\
\hline \multicolumn{4}{|l|}{$\begin{array}{l}\text { Monthly household } \\
\text { income (in Indian } \\
\text { rupees) }\end{array}$} \\
\hline Less than 3000 & 18 (30.5) & $4(6.7)$ & 22 (18.5) \\
\hline $3001-5000$ & $32(54.2)$ & $26(43.3)$ & $57(47.9)$ \\
\hline Above 5000 & $9(15.3)$ & $30(50.0)$ & 39 (32.8) \\
\hline
\end{tabular}

"Missing cases are excluded from the analysis.

staff in Arajiline $(\mathrm{n}=52)$ and rest are spouse/partner/ friends/relatives; whereas in Hosakote multiple source of information has been reported that varies from YIC staff ( $\mathrm{n}=54)$, spouse/partner $(\mathrm{n}=34)$, posters/hoardings/ newspaper $(\mathrm{n}=31)$, school teacher $(\mathrm{n}=12)$ and Accredited Social Health Activist/Auxiliary Nurse Midwife (n = 43). The median \pm SD time to reach YFHS in Arajiline and Hosakote is $15 \pm 9.0$ and $20 \pm 14.7$.
Findings indicate that the largest number of clients in Arajiline have received counselling $(\mathrm{n}=53)$, nutrition supplementation $(\mathrm{n}=45)$ and medical examinations $(\mathrm{n}=$ 41). However, in Hosakote the maximum number of services received by clients is counselling $(n=58)$ and medical examination $(n=55)$. Nearly $66 \%$ of clients visited YFHS to sought treatment for three key health problems i.e. menstruation problems (25.4\%) followed by general illness (22.8\%) and swelling/itching of private parts $(21.1 \%)$. Similar proportions are observed in all study sites.

2) Competency of service providers and attitude towards adolescent

At the time of the survey, the prescribed staff for PHC was available at both the site of Arajiline and Hosakote except the position of female doctor which was lying vacant in Sulibele clinic at the time of the survey. However, it has been noticed that doctors from both the sites of Hosakote and Rajatalab clinic of Arajiline were trained on ARSH. As reported in the clients interview, $71 \%$ of the clients (Arajiline: 76\%; Hosakote: 67\%) experienced that the attitude of the service providers at the ARSH clinic was welcoming.

3) Waiting time and time spend for client and doctor interaction

Results revealed that 37 out of 96 young clients stated that they waited for less than 10 minutes to meet doctor. Most of the clients (75\%) reported that the time spent for client and provider interactions was 5 - 10 minutes in the selected study sites. It is interesting to note that most of the clients $(89 \%)$ described that the time spent by the doctors was appropriate. However few clients reported that the time spend by the provider was "too short" (Table 2).

4) Privacy and confidentiality

As per implementation guide on ARSH [13], audio and visual privacy is crucial during client-provider interaction. The results from the exit interviews suggest that some clients from Arajiline $(\mathrm{n}=25)$ and Hosakote $(\mathrm{n}=4)$ have reported that it was possible for others to see them from outside during the consultation with doctor. Majority of the clients from Hosakote $(\mathrm{n}=58)$ have said that no one was present during the consultation with doctor. On the other hand, 31 clients from Arajiline reported that the support staff/other patients were present during the consultation with doctor. A few clients $(n=9)$ stated that the privacy of unmarried may get disclosed after seeking the services (Table 3). Most of the participants of FGD were of opinion that health providers should reassure privacy to young people particularly in case of unmarried female. In one of the FGD of community members quoted that "If privacy breaks, the family will be blamed and discriminated by other community members and parents and girl may get bad name in the society". 
Table 2. Waiting time and time spend for client and doctor interaction.

\begin{tabular}{cccc}
\hline Indicators & $\begin{array}{c}\text { Arajiline } \\
(\mathrm{n}=41)\end{array}$ & $\begin{array}{c}\text { Hosakote } \\
(\mathrm{n}=55)\end{array}$ & $\begin{array}{c}\text { Total } \\
(\mathrm{n}=96)\end{array}$ \\
\hline $\begin{array}{c}\text { Waiting time to meet } \\
\text { the doctor } \\
<5 \text { minutes }\end{array}$ & $25(61.0)$ & - & $25(26.0)$ \\
5 - 10 minutes & $12(29.3)$ & - & $12(12.5)$ \\
$>10$ minutes & $4(9.8)$ & $55(100)$ & $59(61.5)$ \\
$\begin{array}{c}\text { Time spend for client } \\
\text { and doctor interaction } \\
<5 \text { minutes }\end{array}$ & $10(24.4)$ & - & $10(10.4)$ \\
5 - 10 minutes & $18(43.9)$ & $54(98.2)$ & $72(75.0)$ \\
$>10$ minutes & $13(31.7)$ & $1(1.8)$ & $14(14.6)$ \\
$\begin{array}{c}\text { Perception of client } \\
\text { about the time spend by } \\
\text { the doctor }\end{array}$ & & & \\
Too short & $6(14.6)$ & $2(3.6)$ & $8(8.3)$ \\
Appropriate & $33(80.5)$ & $52(94.5)$ & $85(88.5)$ \\
Too long & $2(4.9)$ & $1(1.8)$ & $3(3.1)$ \\
\hline & & & \\
\hline
\end{tabular}

Table 3. Perception of client about the attitude of YFHS staff towards the visit of an unmarried for contraceptive counseling.

\begin{tabular}{cc}
\hline & $\mathrm{n}=120$ \\
\hline YFHS staff may not inform the parents about & 94 (78.3)
\end{tabular}

Key reasons for the perception

- To maintain confidentiality.

- YFHS staff are trained and they respect privacy.

- It is the right of young people to avail services.

YFHS staff may inform the parents about the visit of unmarried

$9(7.5)$

Key reasons for the perception

- It is a sensitive issue as per our social norm hence providers will not keep the information secret as it reflect the unwanted behavior of the unmarried.

- Parents should know everything about their children particularly if the unmarried is a girl child.

- If providers know the parents then they will inform because they want to be a goody face.

$$
\text { Can't say }
$$

5) Separate space and special times set aside

The YFHS in Arajiline and Hosakote have separate consultation and counseling rooms, waiting area, and record keeping space. In both Arajiline and Hosakote separate consultations timings were available to young people. Majority of the clients (Arajiline: 88.3\%; Hosakote: $86.7 \%$ ) said that the timing and day are convenient for them to seek the services. Earlier studies have shown that when clinic timings are convenient to young people it results in effective recruitment [14].

6) Education materials available at YFHS

Education material has vital role in providing information and generating awareness about the RSH issues and services available at YFHS. Such material can be used while clients are waiting and should be available as take home material to enable young people to learn more $[15,16]$.

Majority of the clients (Arajiline: 76.7\%; Hosakote: 96.7\%) reported that educational materials (book, magazine, poster, pamphlets) on RSH were available in the waiting area during their visit to YFHS. This is also evident from the facility observations. However, very few have reported that they carry the information material with them from the health facility.

7) Satisfaction attained from YFHS and Suggestions to improve the services

In the present study the overall clients' satisfaction with YFHS was assessed as perceived by them. It has been found that the $81.7 \%$ of the client in Arajiline and 95\% in Hosakote were satisfied with the services availed at YFHS. Clients who perceived that the attitude of providers at facility was "welcoming" are more satisfied than those who felt "un-welcoming". Interestingly, clients are less satisfied who had experienced more than 10 minutes or less than 5 minutes of interaction with providers than those who had interacted for 5 - 10 minutes. Results show that a positive association between client satisfaction and privacy maintained in the room during consultation with doctor. Two key characteristics of YFHS i.e. visiting time of YFHS and comfort in talking about the health concern/problem with provider are not found associated with client satisfaction. Clients who reported higher time to reach YFHS and who had waited for more than 10 minutes to meet doctor are more satisfied with the services (Table 4).

As regard to suggestion for improvement in YFHS, most of the clients suggested that more public awareness is required about YFHS (27.6\%), separate waiting room for young people (25.9\%), availability of male and female doctors (12.9\%), separate counseling room (10.3\%) and services should be closer to door-step (8.6\%). Other suggestions made by the clients include equal respect to all patients (5.2\%), services should be available on all seven days (3.4\%) and comfortable surroundings in YFHS (1.7\%).

\subsection{Outreach Activities}

It is well proven that the major health problems for young people are largely preventable [7]. Hence, in order to address RSH needs and to generate demand of YFHS, 
Table 4. Perceived level of satisfaction by experience of the clients on key characteristics of YFHS.

\begin{tabular}{|c|c|c|c|}
\hline $\begin{array}{c}\text { Key Characteristics of } \\
\text { YFHS }\end{array}$ & $\begin{array}{l}\text { Satisfied } \\
\text { from YFHS }\end{array}$ & Ratio & Total \\
\hline \multicolumn{4}{|l|}{$\begin{array}{l}\text { Visiting day/hour are } \\
\text { convenient }\end{array}$} \\
\hline Convenient $^{\circledR}$ & 93 (88.6) & 1.0 & 105 \\
\hline Not convenient & 13 (86.7) & 1.0 & 15 \\
\hline \multicolumn{4}{|l|}{$\begin{array}{l}\text { Time taken to reach } \\
\text { YFHS from residence }\end{array}$} \\
\hline$<30$ mins $^{\circledR}$ & $86(86.0)$ & 1.0 & 100 \\
\hline$>30$ mins & $20(100.0)$ & 1.2 & 20 \\
\hline \multicolumn{4}{|l|}{$\begin{array}{l}\text { Attitude of provider at } \\
\text { reception }\end{array}$} \\
\hline Welcoming ${ }^{\circledR}$ & 77 (90.6) & 1.0 & 85 \\
\hline Not good & 29 (82.9) & 0.9 & 35 \\
\hline \multicolumn{4}{|l|}{$\begin{array}{l}\text { Waiting time to meet } \\
\text { doctor }\end{array}$} \\
\hline$<5$ minutes & $19(76.0)$ & 0.8 & 25 \\
\hline 5 - 10 minutes & $10(83.3)$ & 0.9 & 12 \\
\hline$>10$ minutes $^{\circledR}$ & $55(93.2)$ & 1.0 & 59 \\
\hline \multicolumn{4}{|l|}{$\begin{array}{l}\text { People present in the } \\
\text { room at the time of } \\
\text { consultation with } \\
\text { doctor }\end{array}$} \\
\hline Nobody $^{\circledR}$ & $62(91.2)$ & 1.0 & 68 \\
\hline Other people present & $23(82.1)$ & 0.9 & 28 \\
\hline \multicolumn{4}{|l|}{$\begin{array}{c}\text { Possible to watch } \\
\text { others during } \\
\text { consultation with } \\
\text { doctor }\end{array}$} \\
\hline Yes & 17 (70.8) & 0.8 & 24 \\
\hline $\mathrm{No}^{\circledR}$ & 67 (93.1) & 1.0 & 72 \\
\hline \multicolumn{4}{|l|}{$\begin{array}{l}\text { Client and doctor } \\
\text { interaction }\end{array}$} \\
\hline$<5$ minutes & $9(90.0)$ & 0.9 & 10 \\
\hline 5 - 10 minutes $^{\circledR}$ & 69 (95.8) & 1.0 & 72 \\
\hline$>10$ minutes & $10(71.4)$ & 0.8 & 14 \\
\hline \multicolumn{4}{|l|}{$\begin{array}{l}\text { Comfortable talking to } \\
\text { the health concern } \\
\text { with provider }\end{array}$} \\
\hline Comfortable $^{\circledR}$ & 56 (88.9) & 1.0 & 63 \\
\hline Not Comfortable & 29 (87.9) & 1.0 & 33 \\
\hline \multicolumn{4}{|l|}{$\begin{array}{l}\text { Improvement in health } \\
\text { concern/ problem after } \\
\text { visiting doctor }\end{array}$} \\
\hline Yes $^{\circledR}$ & 45 (91.8) & 1.0 & 49 \\
\hline No & 40 (85.1) & 0.9 & 47 \\
\hline
\end{tabular}

${ }^{*} \mathrm{p}<0.05$. the intervention of MAMTA-HIMC has provided safe place i.e. "YIC" within the community.

1) Role of YIC in motivating client to access YFHS

Result from the exit interviews illustrated that $94 \%$ of clients (Arajiline: $\mathrm{n}=53$; Hasokote: $\mathrm{n}=60$ ) who are seeking services at YFHS had accessed YIC at-least once. Three key reasons for not visiting YIC were reported by the clients in Arajiline (7 out of 60), i.e. long distance, YIC not in the village and uncomfortable to visit YIC.

In addition, out of those clients who had visited YIC atleast once, $92.5 \%$ in Arajiline and 85\% in Hasokote reported that the YIC staff/activities had motivated them to sought services at YFHS. When asked, in what way YIC had motivated, $84.2 \%$ of the clients were of the opinion that YIC had provided right access to correct information on RSH, eliminate myths and misconceptions on RSH (28.3\%). Moreover, some of the clients also reported that counseling and infotainment services of YIC had build confidence to talk freely on RSH issues (14.8\%) and removed fear and stigma related to RSH (10.8\%). Observations from the FGDs revealed that the sensitization and orientation of key influential adults (e.g. members of local governance, school teachers etc) by the YIC staff has promoted positive thinking of the community towards adolescents RSH need. In the FGD of young people of Hosakote has quoted, "The involvement of village panchayats, school teachers and elderly population in the YICs has build-up the environment in the community. Due to this parent has now allowed us to participate in YIC activities".

2) Awareness regarding YIC services/activities

Table 5 illustrates the level of awareness of YIC services/activities among those clients who had accessed YIC $(n=113)$. Major proportion of the clients was aware of various services of YIC, for instance: reading/learning materials e.g. books, posters and other learning materials (99\%), entertainment activities e.g. indoor and outdoor games, some with educational content, competitions (92\%), counseling services (84\%).

3) Attitude of the community towards adolescent

It is noticeable to reveal that $85 \%$ of clients (Arajiline: 73\%; Hasokote: 96\%) perceived "any change" in attitude of adult towards RSH concerns of young people due to YIC activities in last 2 years. Out of those clients who perceived "any change" in the adults, $28.3 \%$ have reported that adults are now receptive in their attitude; $24.2 \%$ said that adults now allowed them to attend YIC meetings but strong objection exist on watching pictures/ videos related to private parts. About $23 \%$ of clients perceived that adults in the community are now more aware of RSH issues consequently allowing young girls to visit YFHS accompanied with any of the family member (9.2\%). A few clients (6.7\%) pointed out that the parents now talk freely with the children on menstrual problems; 
Table 5. Awareness of clients regarding the YIC services/activities.

\begin{tabular}{cccc}
\hline $\begin{array}{c}\text { Key services/ } \\
\text { activities of YIC }\end{array}$ & $\begin{array}{c}\text { Arajiline } \\
(\mathrm{n}=53)\end{array}$ & $\begin{array}{c}\text { Hasokote } \\
(\mathrm{n}=60)\end{array}$ & $\begin{array}{c}\text { Total } \\
(\mathrm{n}=113)\end{array}$ \\
\hline Reading materials & $52(98.1)$ & $60(100)$ & $112(99.1)$ \\
$\begin{array}{c}\text { Entertainment } \\
\text { activities }\end{array}$ & $51(96.2)$ & $53(88.3)$ & $104(92.0)$ \\
$\begin{array}{c}\text { Group activities/ } \\
\text { community meetings }\end{array}$ & $46(86.6)$ & $52(86.7)$ & $98(86.7)$ \\
$\begin{array}{c}\text { Counselling services } \\
\text { Other (a box for } \\
\text { anonymous questions) }\end{array}$ & $43(81.1)$ & $50(83.3)$ & $95(84.1)$ \\
\hline
\end{tabular}

however restrictions exist on sex related issues.

More than half of the participants of FGDs reported that community attitude has changed positively towards the adolescent's concern. However, nearly all the participants from FGD stressed out a need of change in attitude towards female adolescent. One of the quotes of the FGD from community members stated, "The culture of Indian society is like that where parents and young do not talk freely on various personal issues and situation for females are worse in some cases. However, there is a need to break this silence and create a parent-daughter friendly environment in the society".

4) Suggestions for improvement of YIC services/activities

About $31.7 \%$ of the clients reported that awareness activities using new technologies are required and responsibility should be given to the young people in the community. Many clients also illustrated that the YIC should be open every village (20.8\%) and should be linked to livelihood to attract more young people (14.2\%). It is worth noting that some of the clients mentioned the Doctor/ANM/Panchayat members should periodically visit YIC (9.2\%). A few of the respondents also mentioned that YIC activities should focus more on boys. Nearly all the participants of FGD reported that YIC should be established at school/college level and integrated at Gram Panchayat level or with Village Health Committee so as to formulate more effective and sustainable approach.

\section{DISCUSSION}

This study has focused on understanding of key characteristics of "YFHS" primarily through exit interview of the clients from Arajiline and Hosakote blocks. Also, role of community based activities in improving access to YFHS has been assessed. We found that the low proportion of clients of 15 - 19 years, non-Hindu and lower socio-economic group are accessing YFHS. A very few efforts have been seen to take services to such groups [16]. This highlights the need of inclusive interventions to these groups.

The treatment seeking behavior of young people largely depends on many leading factors like awareness regarding the availability of services, knowledge on services offered, and accessibility of services without any discomfort etc. [17]. Study revealed that majority of clients was aware that YFHS provides services to males and females separately and reported that timing and days are convenient for them to seek services. Study indicates that young people usually come to the clinic with considerable fear, often with a worry about privacy and confidentiality, and require strong reassurance and active encouragement to speak freely [18]. Similar findings were observed during FGD of community members and young people. It has been acknowledged from the participants of FGD that treatment seeking behavior may improve if both female and male doctors are available to address the concerns of girls and boys separately. Our findings are in line with various other studies $[19,20]$.

Health service providers specially trained to work competently and sensitively with young people is often considered the single most important condition for establishing YFHS [21,22]. As stated in the implementation guide on ARSH [13], the number of health care providers was in-position in both the study sites; however, gap exists in terms of the trained staff on "adolescent friendly health services". Results from exit interviews indicate that in Hosakote privacy was maintained during consultation with the doctor, however, situation was not adequately maintained in Arajiline. Most of the clients mentioned that they had 5 - 10 minutes interaction with the service provider, which was perceived by them as appropriate. Although times spend during client-provider interaction seems short from a professional point of view, however, this consultation time could suffice if the health condition and reason for consultation were simple enough to allow a diagnosis or address the concern of adolescent. However, this need to be further explored.

In the present study, major proportions of the clients were satisfied with the services availed at the YFHS. In order to understand the differentials in level of client satisfaction, ratios of the levels of satisfaction among the clients by their experience on different key characteristics of YFHS was computed. The attitude of providers and privacy maintained in the consultation room could be the key reasons for high satisfaction. Surprisingly, time factor (time to clinic, waiting time to meet doctor) did not affect the satisfaction level of the services. However, this need to be further explored. Interestingly, higher ratio of clients are satisfied if the client and provider interaction is $5-10$ minutes as compared to less than 5 minutes or more than 10 minutes of interaction. Our findings contrasted with the similar studies [23,24].

Given the challenge of attracting young people to 
clinics, new efforts have emerged as outreach activities to deliver services to locations where young people spend time [22,25]. MAMTA-HIMC initiated an innovative outreach strategy (YIC) to bring together young people for information sharing on RSH and generate demand for service. As evident from the study client perceived that YIC strategies hold significant role for addressing young people needs, taking the services closer to the clients and to increase access to YFHS. Increasing evidence [26] shows that restrictive attitude of parents, due to social norms is an important barrier in adolescent care. Often, adults around the adolescent decide whether or not health care services need to be sought, and if so when and where should be sought. Although "YIC" approach is not intensely focused on attitudinal or behavioral change of adults, hence, significant change in community attitudes have not been observed with regard to adolescent's need. However, most of the clients who perceived change in the attitude of adults, reported that adults exposed YICs, are relatively more receptive in their attitude towards adolescent's concern. Further, clients also perceived that they faced fewer barriers to access YIC/YFHS from those adults who had participated in YIC activities. Nonetheless, barriers still exist in order to allow unmarried girls to visit clinic. This highlights the need of strengthening the YIC approach beyond health sector.

Nearly $32 \%$ of the clients reported that new technologies should be used in YIC to conduct awareness activities and responsibility should be given to the young people. In addition to the well established strategies and approaches of generating demand and changing the community behavior, various new emerging infotainment technologies should be used in YICs for instance use of internet, mobile-phones, multimedia-campaigns etc. Similar approaches are tried in other interventions, which have shown positive effects on behavior change [19,27].

The study had some shortcomings. The study is descriptive in nature; hence inferences drawn are not explanatory and should not be generalized. Sample size was calculated for the study as a whole, therefore conclusions should not be drawn for individual facility. Another limitation relates to the use of exit interviews as a source of client satisfaction. Though exit interviews involve a sample of clients who have already made a choice to appear at specific facility and are likely to believe that the facility will be minimally satisfactory. Nevertheless, it has identified bottlenecks in the service delivery system that need to be addressed to improve the quality of services. Despite limitations, this is the first study to report client perspectives on role of outreach approach i.e. "YIC" in improving access the YFHS in the selected study area.

While majority of the clients were satisfied with the services at YFHS, there is a need for strengthening the existing "package" of the services and expand outreach and community based approaches. At facility level, reassurance about the privacy and confidentially and alternative ways to promote access and utilization of services is recommended. Likewise, at outreach level, new technologies should be introduced to generate demand, intensive focus on adults and integration of YIC with local governance and school environment is suggested.

\section{ACKNOWLEDGEMENTS}

Authors acknowledge the support from The Ministry for Foreign Affairs and group of Physicians for Social Responsibility, Finland.

\section{REFERENCES}

[1] Barker, G. (2003) Engaging adolescent boys and young men in promoting sexual and reproductive health: Lessons, research and programmatic challenges. In: Adolescent and Youth Sexual and Reproductive Health: Charting Directions for a Second Generation of Programming, Population Council, New York, 109-153.

[2] Jejeebhoy, S.J. (1998) Adolescent sexual and reproductive behavior: A review of the evidence from India. Social Science and Medicine, 46, 1275-1290. doi:10.1016/S0277-9536(97)10056-9

[3] Senderowitz, J., Hainsworth, G. and Solter, C. (2003) A rapid assessment of Youth Friendly Reproductive Health Services (YFHS). Pathfinder International, No. 4. http://www2.pathfinder.org/site/DocServer/YFS_TG_Fin al_web_version.pdf?docID=762

[4] Senderowitz J. (1999) Making reproductive health services youth friendly. Focus on Young Adults. Pathfinder International, Washington DC.

[5] Senderowitz, J., et al. (2002) Clinic assessment of youth friendly services: A tool for assessing and improving reproductive health services for youth. Pathfinder International.

http://www.pathfind.org/site/DocServer/mergedYFStool.p df?docID $=521$

[6] Tylee, A., Haller, D.M., Graham, T., Churchill, R. and Sanci, L.A. (2007) Youth-friendly primary-care services: How are we doing and what more needs to be done? Lancet, 369, 1565-1573. doi:10.1016/S0140-6736(07)60371-7

[7] World Health Organisation (2002) Adolescent friendly health services: An impact model to evaluate their effectiveness and cost. World Health Organisation, Geneva.

[8] Society for Adolescent Medicine (2004) Access to health care for adolescents and young adults: Position paper of the Society for Adolescent Medicine. Journal of Adolescent Health, 35, 342-344.

[9] Bhuiya, I., Rob, U., Chowdhury, A., et al. (2004) Improving adolescent reproductive health in Bangladesh Frontiers project final report. Frontiers in reproductive health Population Council, Dhaka. 
[10] NAFCI (2004) Report on activities and progress. National Adolescent-Friendly Clinic Initiative, (NAFCI) Parklands.

[11] Save the Children (2004) Youth-friendly pharmacies in Bolivia. Save the Children, Westport.

[12] MAMTA Health Institute for Mother and Child. www.mamta-himc.org (accessed on 27.4.2012).

[13] Government of India, Ministry of Health and Family Welfare (2006) Implementation Guide on RCH-II. Adolescent Reproductive Sexual Health Strategy (ARSH). Government of India, New Delhi. http://mohfw.nic.in/NRHM/Documents/ARSH/Implemen tation_guide_on_RCH\%20II.pdf

[14] Mclntyre, P., et al. (2002) Adolescents friendly health services: An agenda for change. WHO, Geneva. http://www.who.int/reproductive-health/publications/cah docs/cah 02 14.html

[15] Burns, A., Ruland, C., Finger, W., Murphy-Graham, E., McCarney, R., Schueller, J. (2004) Reaching out-ofschool youth with reproductive and HIV information and services: Youth issues papers. Family Health International, YouthNet Program, Arlington.

[16] Moya, C. (2002) Creating youth friendly sexual health services in sub Saharan Africa. http://www.advocatesforyouth.org/component/content/arti cle/549-creating-youth-friendly-sexual-health-services-insub-saharan-africa

[17] Sanci, L.A., Sawyer, S.M., Kang, M.S., Haller, D.M. and Patton, G.C. (2005) Confidential health care for adolescents: Reconciling clinical evidence with family values. The Medical Journal of Australia, 183, 410-414.

[18] Blum, R.W., Halcon, L., Beuhring, T., Pate, E., CampellForrester, S. and Venema, A. (2003) Adolescent health in the Caribbean: Risk and protective factors. American Journal of Public Health, 93, 456-460. doi:10.2105/AJPH.93.3.456

[19] Barber, B.K., Stolz, H.E. and Olsen, J.A. (2005) Parental support, psychological control, and behavioral control: Assessing relevance across time, culture, and method.
Monographs of the Society for Research in Child Development, 70, 1-137.

[20] Brabin, L. (1995) Preventative and curative care for adolescents: The role of the health sector. WHO/UNFPA/ UNICEF Study Group on Programming for Adolescent Health, 28 November-4 December.

[21] Erulkar, A.S. and B.S., Mensch. (1997) Youth Centres in Kenya: Evaluation of the Family Planning Association of Kenya Programme. Population Council, Inc., Nairobi.

[22] Lebow, J.L. (1983) Research assessing consumer satisfaction with mental health treatment: A review of findings. Evaluation and Program Planning, 6, 211-236. doi:10.1016/0149-7189(83)90003-4

[23] Mendoza, A.J., Piechulek, H. and Al-Sabir, A. (2001) Client satisfaction and quality of health care in rural Bangladesh. Bulletin of the World Health Organization: The International Journal of Public Health, 79, 512-517.

[24] Patro, B.K., Kumar, R., Goswami, A., Nongkynrih, B. and Pandav, C.S. (2008) Community perception and client satisfaction about the primary health care services in an urban resettlement colony of New Delhi. Indian Journal of Community Medicine, 33, 250-254.

[25] Ortola, P., Blanquer, J.J., Rodriquez, J.J., Rodrigo, O., Villagrasa, F. and Climent, J.A. (1993) User satisfaction in primary care: Result of a home survey. Atencion Primaria, 12, 578-579.

[26] Anteghini, M., Fonseca, H., Ireland, M. and Blum, R.W. (2001) Health risk behaviors and associated risk and protective factors among Brazilian adolescents in Santos, Brazil. Journal of Adolescent Health, 28, 295-302. doi:10.1016/S1054-139X(00)00197-X

[27] Lau, P.W., Lau, E.Y., Wong, D.P. and Ransdell, L. (2011) A systematic review of information and communication technology-based interventions for promoting physical activity behavior change in children and adolescents. Journal of Medical Internet Research, 13, e48. doi:10.2196/jmir.1533 